\title{
A Dual-loop Model Predictive Voltage Control/Sliding-mode Current Control for Voltage Source Inverter Operation in Smart Microgrids
}

\author{
Khaled M. Abo-Al-Ez, ${ }^{1,2}$ Ahmed Elaiw, ${ }^{2,3}$ and Xiaohua Xia ${ }^{2}$ \\ ${ }^{1}$ Department of Electrical Engineering, Faculty of Engineering, Mansoura University, Mansoura, Egypt \\ ${ }^{2}$ Centre of New Energy Systems, Department of Electrical, Electronic and Computer Engineering, University of Pretoria, \\ South Africa \\ ${ }^{3}$ Department of Mathematics, Faculty of Science, King Abdulaziz University, Jeddah, Saudi Arabia
}

\begin{abstract}
The design of a robust controller for the voltage source inverter is essential for reliable operation of distributed energy resources in future smart microgrids. The design problem is challenging in the case of autonomous operation subsequent to an islanding situation. In this article, a dual-loop controller is proposed for voltage source inverter control. The outer loop is designed for microgrid voltage and frequency regulation based on the model predictive control strategy. This outer loop generates reference inverter currents for the inner loop. The inner loop is designed using a sliding-mode control strategy, and it generates the pulse-width modulation voltage commands to regulate the inverter currents. A standard space vector algorithm is used to realize the pulse-width modulation voltage commands. Performance evaluation of the proposed controller is carried out for different loading scenarios. It is shown that the proposed dual-loop controller provides the specified performance characteristics of an islanded microgrid with different loading conditions.
\end{abstract}

\section{CONTENTS}

1. Introduction

2. State-Space Modeling of Three-Phase Inverter of the Microgrid

3. Design of the Microgrid Controller

4. Performance Evaluation

5. Conclusion

References

Keywords: Smart microgrid, voltage source inverter, model predictive voltage control, sliding-mode current control, robust control, smart grid

Address correspondence to Dr. Ahmed Elaiw, Centre of New Energy Systems, Department of Electrical, Electronic, and Computer Engineering, University of Pretoria, Pretoria, 0002, South Africa. E-mail: a_m_elaiw@ yahoo.com

\section{INTRODUCTION}

There has been a great need to fulfill increasing demands in the energy sector for the last decade. The need for sustainable and reliable electricity supply requires active power distribution networks. This promotes the possibility of bidirectional power flow between the main grid and the consumers. Therefore, the design of future distribution grids is moving away from traditional radial systems toward more networked grids [1]. In this scenario, the self-controlled smart microgrid (SMG) concept is a promising approach. The smart grid concept has been introduced to overcome problems of the power systems and to achieve desired functionalities, such as self-healing, high reliability, high power quality, and accommodation of a wide variety of distributed generation (DG) and storage options [2]. To prevent power system mal-operation and instability, the process of the self-healing procedure should be as fast as possible. 
This is not achievable unless new progress in computational modeling and optimization methods is used [3].

In the new energy generation and consumption model, a key role is played by the SMG, i.e., clusters of distributed energy resources (DERs) supporting local loads for which energy deficiencies or production excesses are solved by exchanging power with the utility. DERs provide the advantage to users of exploitation of renewable sources thus reducing the production costs [4]. The SMG permits several intelligent functions that ensure consumer power reliability and optimize the use of energy, mitigate environmental and power quality related impacts, and manage the energy prices and overall costs [5].

SMGs contain smart energy efficient end-use devices, DERs, advanced whole-building control systems, and integrated communications architecture [6]. Most modern DERs, such as microturbines, photovoltaic systems, fuel cells, etc., are load/grid interfaced through power electronic voltage source inverters (VSIs) [7]. According to [8], the SMG concept assumes a cluster of loads and micro-sources, operating as a single controllable system, where the inverter plays a key role for a SMG to participate in energy management and voltage and frequency control.

The SMG is managed by controlling the VSI interface of the DERs to work either as islanded or synchronized to the main electric grid. Upon separation from the main grid, the current operation standard prohibits the autonomous operation of the microgrid due to safety issues [9]. In [8], it was stated that "Upon separation from a utility system, if a smart grid DG stays stable, the inverter of the DG system regulates its frequency. If there is only one inverter in the DG system, load frequency control is accomplished through inverter reference frequency using the PWM technique" (p. 20). The management and control for the SMG are high non-linear problems that are not only related to the environmental/economic optimization problem but also to frequency/voltage security and dynamic stabilization in multi-mode operation [10].

The main challenge for islanded microgrid operation is to provide the VSI with a controller that regulates voltage and frequency despite load variation; droop control is widely used, as reported in [11-15]. In this control approach, the frequency and voltage of each DER unit is a linear function of active power and reactive power respectively. A major drawback of this approach is that it is intended for a fixed load and cannot accommodate large variations in the load parameters. To overcome this drawback, the control design uses one of the microgrid inverters to operate with voltage-frequency (V-f) control to stabilize the microgrid voltage and frequency subsequent to islanding situation. When the DC architecture is adopted, only one inverter is used with the required controller. In the case of AC architecture, as adopted in [16], one of the microgrid
VSIs is controlled in V-f control mode, while other inverters are controlled for active/reactive power (P-Q) control.

DC microgrids are gaining high momentum under the smart grid environment. In a DC microgrid system, a bidirectional pulse-width modulated (PWM) AC-DC VSI is used to interface the DC microgrid to an AC system. Within the DC microgrid, DG units, such as photovoltaic cells, microturbines, and wind turbines, are integrated. Storage units are also available to provide energy backup for critical loads [17].

Some recent research addressed the issue of inverter control in SMGs [18-21]. In [18], a microgrid VSI control scheme was proposed based on $H^{\infty}$ optimal control method to provide a robust performance in the presence of the variation of power factor correction capacitors. Although the $H^{\infty}$ approach is effective for providing robust stability, it may not guarantee voltage tracking capabilities under loading parameters uncertainty. In [19], a repetitive controller of a VSI in a microgrid was designed. This controller is difficult to stabilize for all unknown load disturbances and cannot obtain a very fast response for a fluctuating load. In [21], a robust servomechanism problem (RSP) control was presented for autonomous operation of a single-DG islanded microgrid with a structurally uncertain plant. The parametric uncertainty is due to load variation about their rated values. The design an uses only RSP controller for voltage and frequency control of the microgrid. In [20], RSP control is implemented by the internal model principle. This controller is used for the outer voltage loop of a microgrid VSI showing robust performance.

A discrete-time sliding-mode current controller is used as an inner control loop to the RSP voltage controller for the purposes of overload protection. In this method, a current-limiting function is employed to limit the inverter current commands generated by the RSP voltage controller. This limiting function is not included in the design of an RSP voltage controller. Large overshoot can occur when not using a current limiter, which damages the inverter device. Moreover, some authors [22] do not appreciate the complexity of the method and consider that "the main problem of the RSP controller is the need for relatively hard design" (p. 465).

The hard design of the RSP controller method was discussed in [23] for studying the properties of a closed-loop sampled data system for the RSP. It was shown that fundamental limitations exist on the closed-loop performance of the RSP for a minimum phase sampled system, which are independent of the order of the plant, and of the transmission zero structure of the continuous plant model. It was also shown that fundamental limitations exist on the closed-loop performance of the RSP for a non-minimum phase sampled system in the case of tracking and regulation due to disturbances in the output. 
To overcome the load variation and the "hard" design problems, the design of model predictive control (MPC) is considered for voltage and frequency regulation in an islanded microgrid. The advantages of the MPC over the RSP include its facility of handling constraints and being able to use simple models; it presents good tracking performance that is necessary in industrial applications, offers closed-loop stability, and has inherent robustness [24]. In recent decades, MPC has become one of the most widely used multi-variable control algorithms in various industries, including chemical engineering, food processing, automotive, aerospace applications [25], and recently in power systems [26-32]. In MPC, a finite horizon optimal control problem is repeatedly solved, and the input applied to the system is based on the obtained optimal open-loop control [24]. Recently, an unconstrained MPC approach was presented for the voltage regulation of an islanded inverter of a DG unit [22]. In [22], the constraint on the currents of the inverter was neglected; further, load parameters were incorporated in the control procedure, which is impractical and requires real-time update of the model and control design parameters. In [22], the state-space model of the microgrid did not consider the parameters of the transformer that is used to connect the microgrid to the main grid.

In the present article, a self-controlled microgrid is investigated. The coupling VSI is equipped with a smart controller that can accommodate the islanded mode of operation despite change in loading conditions. The issue of smart voltage and frequency control is addressed to ensure stable operation for consumer loads on one hand and the different renewable generation and storage systems connected on a common DC bus on the other hand. This article proposes a robust dual-loop model predictive voltage control/sliding-mode current control strategy to regulate the voltage and frequency of an islanded microgrid with different loading conditions. The inner loop is designed using a sliding-mode control to limit the inverter current under overload conditions. The outer loop is designed using a constrained MPC to regulate the microgrid load voltages to their reference values. The benefit of this design is that it takes full advantage of the fast response in controlling the inverter current by sliding mode [20] on the one hand, it makes use of the inherent capability of handling constraints of MPC on the other. This article is organized as follows. Section 2 describes the state-space mathematical modeling of the threephase inverter of the microgrid. The dual-loop controller detailed design for the microgrid island is carried out in Section 3. Performance evaluation of the proposed controller is done for various operation scenarios using MATLAB/Simulink in Section 4. Finally, Section 5 concludes the article.

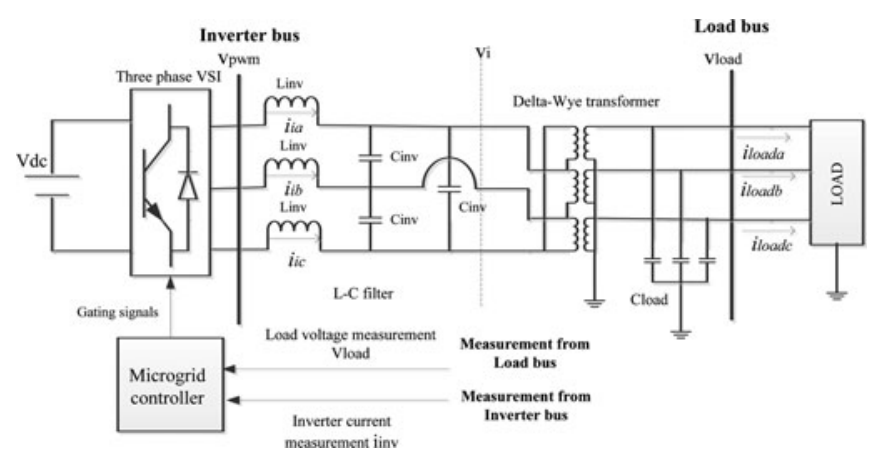

FIGURE 1. Three-phase inverter interface of DC architecture microgrid.

\section{STATE-SPACE MODELING OF THREE-PHASE INVERTER OF THE MICROGRID}

The three-phase inverter system considered herein is a PWM inverter used for DER units, as shown in Figure 1. A constant DC source is used to model most typical types of DER units for the purposes of controller design. This approximate modeling is reasonable when a mix of DER units operates with energy storage systems with a DC architecture. A typical three-phase PWM voltage inverter is used, with an L-C output filter (with inductance $L_{i n v}$ and capacitance $C_{i n v}$ ) and a delta-wye transformer (with resistance $R_{T}$ and inductance $L_{T}$ ) that acts as both a voltage transformer and an electrical isolation to the load. Small capacitors (denoted as $C_{\text {load }}$ ) are added at the load side to provide further harmonic filtering and stabilization of the load voltage [8]. According to [8], it is assumed that the PWM space vector and power converter generate ideal voltages according to the commands given by the control. This assumption is valid due to the relatively high switching frequency of the PWM inverter [8]. The state-space model of the microgrid system in a three-phase $a b c$ reference frame is derived based on Kirchhoff's current and voltage laws and is given by the following equations:

$$
\begin{aligned}
\frac{d \vec{V}_{i_{a b c}}}{d t} & =\frac{1}{3 C_{i n v}} \cdot \vec{I}_{i_{a b c}}-\frac{1}{3 C_{i n v}} \cdot T_{r i} \cdot \vec{I}_{s d_{a b c}}, \\
\frac{d \vec{I}_{i_{a b c}}}{d t} & =\frac{1}{L_{i n v}} \cdot \vec{V}_{p w m_{a b c}}-\frac{1}{L_{i n v}} \cdot \vec{V}_{i_{a b c}}, \\
\frac{d \vec{V}_{\text {Load }_{a b c}}}{d t}= & \frac{1}{C_{\text {Load }}} \cdot \vec{I}_{s d_{a b c}}-\frac{1}{C_{\text {Load }}} \cdot \vec{I}_{\text {Load }_{a b c}}, \\
\frac{d \vec{I}_{s d_{a b c}}}{d t}= & \frac{-R_{T}}{L_{T}} \cdot \vec{I}_{s d_{a b c}}+\frac{1}{L_{T}} \cdot T_{r v} \cdot \vec{V}_{i_{a b c}} \\
& -\frac{1}{L_{T}} \cdot \vec{V}_{\text {Load }_{a b c}}
\end{aligned}
$$


where $\vec{V}_{i_{a b c}}, \vec{V}_{\text {Load }_{a b c}}$, and $\vec{V}_{p w m_{a b c}}$ represent the inverter voltages, load voltages, and PWM voltages in the $a b c$ reference frame, respectively. As a notational convention, a vector in the $x y z$ reference frame is denoted as $\vec{V}_{x y z}=\left[\begin{array}{lll}V_{x} & V_{y} & V_{z}\end{array}\right]^{T}$. Vectors $\vec{I}_{i_{a b c}}, \vec{I}_{\text {Load }_{a b c}}$, and ${\overrightarrow{I_{s d}}}_{a b c}$ denote the inverter currents, load currents, and transformer secondary side currents in the $a b c$ reference frame, respectively. Matrices $T_{r i}$ and $T_{r v}$ denote the current and voltage transformation of the delta-wye transformer, given by

$T_{r i}=t_{r} \cdot\left[\begin{array}{ccc}1 & -2 & 1 \\ 1 & 1 & -2 \\ -2 & 1 & 1\end{array}\right], \quad T_{r v}=t_{r} \cdot\left[\begin{array}{ccc}0 & 0 & -1 \\ -1 & 0 & 0 \\ 0 & -1 & 0\end{array}\right]$,

where $t_{r}$ is the transformer turns ratio.

The design of the proposed control technique requires that the dynamic equations of the system in the three-phase $a b c$ reference frame are transformed into the $q d 0$ stationary reference frame as follows [8]:

$$
\vec{V}_{\cdot d q 0}=K_{s} \cdot \vec{V}_{a b c}, \quad \vec{I}_{\cdot d q 0}=K_{s} \cdot \vec{I}_{a b c},
$$

where $\vec{V}$ can be $\vec{V}_{i}, \vec{V}_{\text {Load }}, \vec{V}_{\text {pwm }}$; and $\vec{I}$ can be $\vec{I}_{i}, \vec{I}_{\text {Load }}$, and $\vec{I}_{s d}$. The transformation matrix $K_{s}$ is given as

$$
K_{s}=\frac{2}{3}\left[\begin{array}{ccc}
1 & \frac{-1}{2} & \frac{-1}{2} \\
0 & \frac{-\sqrt{3}}{2} & \frac{\sqrt{3}}{2} \\
\frac{1}{2} & \frac{1}{2} & \frac{1}{2}
\end{array}\right] .
$$

Using the above voltage and current transformation equations, the state-space equations of the three-phase inverter system in a $d q 0$-axis reference frame can be written as

$$
\begin{aligned}
\frac{d \vec{V}_{i_{q d 0}}}{d t} & =\frac{1}{3 C_{i n v}} \cdot \vec{I}_{i_{q d 0}}-\frac{1}{3 C_{i n v}} \cdot T_{r i_{q d 0}} \cdot \vec{I}_{s d_{q d 0}}, \\
\frac{d \vec{I}_{i_{q d 0}}}{d t}= & =\frac{1}{L_{i n v}} \cdot \vec{V}_{p w m_{q d 0}}-\frac{1}{L_{i n v}} \cdot \vec{V}_{i_{q d 0}}, \\
\frac{d \vec{V}_{L_{\text {oad }} d d 0}}{d t}= & \frac{1}{C_{\text {Load }}} \cdot \vec{I}_{s d_{q d 0}}-\frac{1}{C_{\text {Load }}} \cdot \vec{I}_{\text {Load d d }_{q}}, \\
\frac{d \vec{I}_{s d_{q d 0}}}{d t}= & \frac{-R_{T}}{L_{T}} \cdot \vec{I}_{s d_{q d 0}}+\frac{1}{L_{T}} \cdot T_{r v_{q d 0}} \cdot \vec{V}_{i_{q d 0}} \\
& -\frac{1}{L_{T}} \cdot \vec{V}_{\text {Load }_{q d 0}},
\end{aligned}
$$

where $T_{r i_{q d 0}}=K_{s} \cdot T_{r i} \cdot K_{s}^{-1}$ and $T_{r v_{q d 0}}=K_{s} \cdot T_{r v} \cdot K_{s}^{-1}$.

The zero reference components of the inverter voltages and currents will always be zero and can be discarded for a balanced three-wire system of the inverter and balanced loads. The zero components of the load voltages, load currents, and secondary transformer currents can be non-zero under unbalanced load conditions; however, these components are non-controllable and have no use for control [8].

In this case, the above equations in the $d q 0$ can be simplified in the $d q$ frame as

$$
\begin{aligned}
\frac{d \vec{V}_{i_{q d}}}{d t} & =\frac{1}{3 C_{i n v}} \cdot \vec{I}_{i_{q d}}-\frac{1}{3 C_{i n v}} \cdot T_{r i_{q d}} \cdot \vec{I}_{s d_{q d}} \\
\frac{d \vec{I}_{i_{q d}}}{d t} & =\frac{1}{L_{i n v}} \cdot \vec{V}_{p w m_{q d}}-\frac{1}{L_{i n v}} \cdot \vec{V}_{i_{q d}} \\
\frac{d \vec{V}_{\text {Load }_{q d}}}{d t} & =\frac{1}{C_{\text {Load }}} \cdot \vec{I}_{s d_{q d}}-\frac{1}{C_{\text {Load }}} \cdot \vec{I}_{\text {Load } q d_{q}} \\
\frac{d \vec{I}_{s d_{q d}}}{d t} & =\frac{-R_{T}}{L_{T}} \cdot \vec{I}_{s d_{q d}}+\frac{1}{L_{T}} \cdot T_{r v_{q d}} \cdot \vec{V}_{i_{q d}}-\frac{1}{L_{T}} \cdot \vec{V}_{\text {Load }_{q d}} \\
T_{r i_{q d}} & =\frac{3}{2} t_{r} \cdot\left[\begin{array}{cc}
1 & \sqrt{3} \\
-\sqrt{3} & 1
\end{array}\right] \\
T_{r v_{q d}} & =\frac{1}{2} t_{r} \cdot\left[\begin{array}{cc}
1 & -\sqrt{3} \\
\sqrt{3} & 1
\end{array}\right]
\end{aligned}
$$

The state variables of the system are $\vec{V}_{i_{q d}}, \vec{I}_{i_{q d}}, \vec{V}_{\text {Load }_{q d}}$, and $\vec{I}_{s d_{q d}}$; the control input of the system is $\vec{V}_{p w m_{q d}}$; and $\vec{I}_{\text {Load }_{q d}}$ is treated as a disturbance.

The continuous-time model in Eqs. (9) and (12) is rewritten as

$$
\begin{aligned}
& \dot{x}=A_{s} x+B_{s} u+E_{s} d, \\
& y=C_{s} x+D_{s} u,
\end{aligned}
$$

where the state variable, input, output and disturbance are

$$
\begin{aligned}
& x=\left[\begin{array}{lllllllll}
V_{i_{q}} & V_{i_{d}} & I_{i_{q}} & I_{i_{d}} & V_{\text {Load }_{q}} & V_{\text {Load }_{d}} & I_{s d_{q}} & I_{s d_{d}}
\end{array}\right]^{T}, \\
& u=\left[\begin{array}{ll}
V_{\text {pwm }_{q}} & V_{\text {pwm }_{d}}
\end{array}\right]^{T}, \quad y=\left[\begin{array}{ll}
V_{\text {Load }_{q}} & V_{\text {Load }_{d}}
\end{array}\right]^{T}, \\
& d=\left[\begin{array}{ll}
I_{\text {Load }_{q}} & I_{\text {Load }_{d}}
\end{array}\right]^{T},
\end{aligned}
$$

respectively, and

$$
\begin{aligned}
A_{s} & =\left[\begin{array}{cccc}
\mathbf{0}_{2 \times 2} & \frac{1}{3 C_{i n v}} \cdot I_{2 \times 2} & \mathbf{0}_{2 \times 2} & \frac{-1}{3 C_{i n v}} \cdot T_{r i_{q d}} \\
\frac{-1}{L_{i n v}} \cdot I_{2 \times 2} & \mathbf{0}_{2 \times 2} & \mathbf{0}_{2 \times 2} & \mathbf{0}_{2 \times 2} \\
\mathbf{0}_{2 \times 2} & \mathbf{0}_{2 \times 2} & \mathbf{0}_{2 \times 2} & \frac{1}{C_{\text {Load }}} \cdot I_{2 \times 2} \\
\frac{1}{L_{T}} \cdot T_{r v} & \mathbf{0}_{2 \times 2} & \frac{-1}{L_{T}} \cdot I_{2 \times 2} & \frac{-R_{T}}{L_{T}} \cdot I_{2 \times 2}
\end{array}\right], \\
B_{S} & =\left[\begin{array}{c}
\mathbf{0}_{2 \times 2} \\
\frac{1}{L_{i n v}} \cdot I_{2 \times 2} \\
\mathbf{0}_{2 \times 2} \\
\mathbf{0}_{2 \times 2}
\end{array}\right],
\end{aligned}
$$


$E_{s}=\left[\begin{array}{c}\mathbf{0}_{2 \times 2} \\ \mathbf{0}_{2 \times 2} \\ \frac{-1}{C_{\text {Load }}} \cdot I_{2 \times 2} \\ \mathbf{0}_{2 \times 2}\end{array}\right], \quad C_{s}=\left[\begin{array}{llll}\mathbf{0}_{2 \times 2} & \mathbf{0}_{2 \times 2} & I_{2 \times 2} & \mathbf{0}_{2 \times 2}\end{array}\right]$ $D_{s}=\left[\mathbf{0}_{2 \times 2}\right]$.

In this article, the controller design is based on the nominal continuous-time model of the system shown in Eqs. (13) and (14).

\section{DESIGN OF THE MICROGRID CONTROLLER}

The proposed control strategy uses a dual-loop control structure of the following controllers:

1. inner sliding-mode inverter currents control loop and

2. outer model predictive load voltages control loop.

The outer loop regulates the load voltages to follow the 50or $60-\mathrm{Hz}$ balanced three-phase reference voltages, which are decided by the microgrid operators. This voltage control loop generates the inverter current set values, which are limited. The inner current control loop generates the PWM gating voltages to regulate the inverter currents to follow the inverter currents set values [8]. Figure 2 shows the block diagram presenting the control structure.

A standard voltage space vector algorithm is used to realize the PWM command voltages applied to the VSI. In the next two subsections, the design of the proposed dual-loop controller is given. The discrete-time state-space equations are adopted for the two-loop control design in the $d q$ stationary reference frame.

\subsection{Discrete-time Sliding-mode Current Controller}

The discrete-time sliding-mode controller is used in the inner current control loop to limit the inverter current under overload conditions because it provides fast and non-overshoot response [8]. To design the discrete-time sliding-mode current

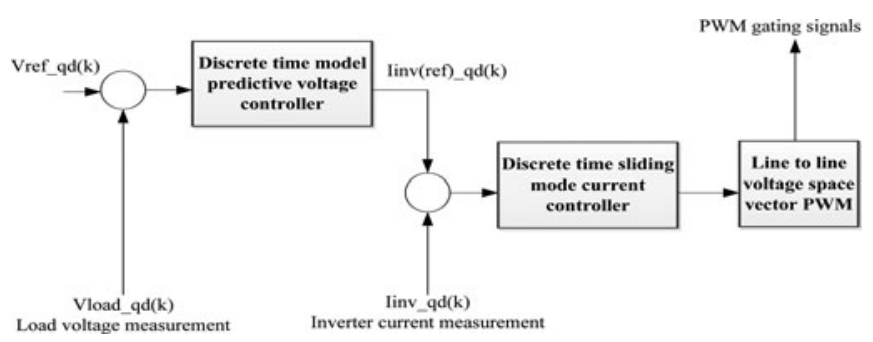

FIGURE 2. Proposed MPC/Sliding-mode controller structure. controller, the model of the three-phase inverter with an L-C filter is considered without the transformer and load. The secondary transformer current ${\overrightarrow{I_{s}}}_{q d}$ is treated as a disturbance to the current controller. The state equations describing the system used for controller design are Eqs. (9) and (10). The statespace representation is as follows:

$$
\begin{aligned}
\dot{x}_{1}= & A_{1} x_{1}+B_{1} u_{1}+E_{1} d_{1}, \\
y_{1}= & C_{1} x_{1}+D_{1} u_{1}, \\
A_{1}= & {\left[\begin{array}{cc}
\mathbf{0}_{2 \times 2} & \frac{1}{3 C_{i n v}} \cdot I_{2 \times 2} \\
\frac{-1}{L_{i n v}} \cdot I_{2 \times 2} & \mathbf{0}_{2 \times 2}
\end{array}\right], \quad B_{1}=\left[\begin{array}{c}
\mathbf{0}_{2 \times 2} \\
\frac{1}{L_{i n v}} \cdot I_{2 \times 2}
\end{array}\right], } \\
E_{1}= & {\left[\begin{array}{c}
\frac{-1}{3 C_{i n v}} \cdot T_{r i_{q d}} \\
\mathbf{0}_{2 \times 2}
\end{array}\right], \quad C_{1}=\left[\begin{array}{ll}
\mathbf{0}_{2 \times 2} & I_{2 \times 2}
\end{array}\right], \quad D_{1}=\left[\mathbf{0}_{2 \times 2}\right], }
\end{aligned}
$$

and the internal state, input, outputs and disturbance are

$$
\begin{aligned}
& x_{1}=\left[\begin{array}{llll}
V_{i_{q}} & V_{i_{d}} & I_{i_{q}} & I_{i_{d}}
\end{array}\right]^{T}, \quad u_{1}=\left[\begin{array}{ll}
V_{p w m_{q}} & V_{p w m_{d}}
\end{array}\right]^{T}, \\
& y_{1}=\left[\begin{array}{ll}
I_{i_{q}} & I_{i_{d}}
\end{array}\right]^{T}, \quad d_{1}=\left[\begin{array}{ll}
I_{s d_{q}} & I_{s d_{d}}
\end{array}\right]^{T} .
\end{aligned}
$$

The state-space equations (Eqs. (15) and (16)) are transformed to a discrete form as follows:

$$
\begin{aligned}
x_{1}(k+1) & =A_{1}^{*} x_{1}(k)+B_{1}^{*} u_{1}(k)+E_{1}^{*} d_{1}(k), \\
y_{1}(k) & =C_{1}^{*} x_{1}(k)+D_{1}^{*} u_{1}(k),
\end{aligned}
$$

where

$$
\begin{aligned}
& A_{1}^{*}=e^{A_{1} T_{s}}, \quad B_{1}^{*}=\int_{0}^{T_{s}} e^{A_{1}\left(T_{s}-\tau\right)} B_{1} d \tau, \\
& E_{1}^{*}=\int_{0}^{T_{s}} e^{A_{1}\left(T_{s}-\tau\right)} E_{1} d \tau, \quad C_{1}^{*}=C_{1}, \quad D_{1}^{*}=D_{1},
\end{aligned}
$$

and $T_{s}$ is the sampling period, which, in this case, is equal to the PWM period [8]. To force the inverter currents to follow their set values (decided by the voltage controller), the sliding-mode surface is chosen such that

$$
\begin{aligned}
S(k) & =y_{1}(k)-y_{1, r e f}(k)=C_{1}^{*} x_{1}(k)-y_{1, \text { ref }}(k) \\
& =\vec{I}_{i_{q d}}-\vec{I}_{i_{q d}, \text { ref }} .
\end{aligned}
$$

Thus, the sliding surface $S(k)$ is selected such that when the discrete sliding-mode exists,

$$
S(k)=0 \quad \text { or } \quad \vec{I}_{i_{q d}}=\vec{I}_{i_{q d}, r e f}
$$

The discrete-time sliding mode can be reached if control input $u_{1}(k)$ is designed to be the solution of the following:

$$
S(k+1)=y_{1}(k+1)-y_{1, r e f}(k+1) .
$$

The control law that satisfies the above equation is known as equivalent control and can be derived as follows:

$$
S(k+1)=C_{1}^{*} x_{1}(k+1)-\vec{I}_{i_{q d}, r e f}=0 .
$$


Then, from Eq. (17), the equivalent control to be implemented in the inner current control loop can be obtained as

$$
u_{1_{e q}}(k)=\left(C_{1}^{*} B_{1}^{*}\right)^{-1}\left[\vec{I}_{i_{q d}, r e f}-C_{1}^{*} A_{1}^{*} x_{1}(k)-C_{1}^{*} E_{1}^{*} d_{1}(k)\right] .
$$

\subsection{Discrete Time Model Predictive Voltage Controller}

Since the MPC is the outer loop, the plant seen by the voltage controller is the combination of the true plant (three-phase inverter with an L-C filter and the transformer) along with the discrete-time sliding-mode current controller. To design the voltage controller, the following discrete-time nominal model of Eqs. (13) and (14) is used:

$$
\begin{aligned}
x(k+1) & =A_{s}^{*} x(k)+B_{s}^{*} u(k), \\
y(k) & =C_{s}^{*} x(k)+D_{s}^{*} u(k),
\end{aligned}
$$

where the state variable, input, and output are

$$
\begin{aligned}
& x=\left[\begin{array}{llllllll}
V_{i_{q}} & V_{i_{d}} & I_{i_{q}} & I_{i_{d}} & V_{\text {Load }_{q}} & V_{\text {Load }_{d}} & I_{s d_{q}} & I_{s d_{d}}
\end{array}\right]^{T}, \\
& u=\left[\begin{array}{ll}
V_{\text {pwm }_{q}} & V_{p w m_{d}}
\end{array}\right]^{T}, \quad y=\left[\begin{array}{ll}
V_{\text {Load }_{q}} & V_{\text {Load }_{d}}
\end{array}\right]^{T}, \\
& A_{s}^{*}=e^{A_{s} T_{s}}, \quad B_{1}^{*}=\int_{0}^{T_{s}} e^{A_{s}\left(T_{s}-\tau\right)} B_{s} d \tau, \quad C_{s}^{*}=C_{s} D_{s}^{*}=D_{s} .
\end{aligned}
$$

The load voltage reference to be tracked by the MPC is generated in the $a b c$ reference frame then transformed to the $q d$ needed for the controller. The referene phase to neutral load voltages in the $a b c$ frame is given by

$$
\begin{aligned}
& V_{\text {Load, ref, an }}(k)=V_{m} \sin \left(2 \pi \cdot f_{\text {ref }} \cdot k \cdot T_{s}\right), \\
& V_{\text {Load, }, e f, b n}(k)=V_{m} \sin \left(2 \pi \cdot f_{\text {ref }} \cdot k \cdot T_{s}-\frac{2 \pi}{3}\right) \text {, } \\
& V_{\text {Load, } r e f, c n}(k)=V_{m} \sin \left(2 \pi \cdot f_{\text {ref }} \cdot k \cdot T_{s}+\frac{2 \pi}{3}\right),
\end{aligned}
$$

where $V_{m}$ is the phase voltage magnitude, and $f_{\text {ref }}$ is the fundamental reference frequency.

The load voltage reference in the $q d 0$ frame is given by

$$
\begin{aligned}
\vec{V}_{\text {Load,ref,abc }} & =\left[\begin{array}{lll}
V_{\text {Load,ref,an }} & V_{\text {Load,ref,bn }} & V_{\text {Load,ref,cn }}
\end{array}\right]^{T}, \\
\vec{V}_{\text {Load,ref,qd0 } 0} & =K_{s} \cdot \vec{V}_{\text {Load, ref,abc }} \\
& =\left[\begin{array}{lll}
V_{\text {Load,ref,q }} & V_{\text {Load,ref,d }} & V_{\text {Load,ref, },}
\end{array}\right]^{T} .
\end{aligned}
$$

Again, only the $q d$ componenets are needed for the MPC design:

$$
\vec{V}_{\text {Load,ref,qd }}=\left[\begin{array}{ll}
V_{\text {Load,ref,q }} & V_{\text {Load,ref, },}
\end{array}\right]^{T} .
$$

\subsubsection{The Augmented Plant of the Voltage Controller}

To augment the discrete-time sliding-mode controller in the plant, the control law of the discrete-time sliding-mode current controller $u_{1_{e q}}(k)$ is used to equal $u(k)$ in Eqs. (20) and (21); so, with substitution in those equations;

$$
\begin{aligned}
x(k+1)= & A_{s}^{*} x(k)+B_{s}^{*}\left(C_{1}^{*} B_{1}^{*}\right)^{-1} \\
& \times\left[\vec{I}_{i_{q d}, \text { ref }}-C_{1}^{*} A_{1}^{*} x_{1}(k)-C_{1}^{*} E_{1}^{*} d_{1}(k)\right] .
\end{aligned}
$$

The inverter current set value is the input of the MPC of the voltage; therefore $u_{v}(k)=\left[\begin{array}{ll}I_{i_{q}}, \text { ref } & I_{i_{d}}, \text { ref }\end{array}\right]^{T}$. Then Eqs. (20) and (21) become

$$
\begin{aligned}
x_{v}(k+1) & =A_{v}^{*} x_{v}(k)+B_{v}^{*} u_{v}(k), \\
y_{v}(k) & =C_{v}^{*} x_{v}(k),
\end{aligned}
$$

where

$$
\begin{aligned}
& A_{v}^{*}=A_{s}^{*}-B_{s}^{*}\left(C_{1}^{*} B_{1}^{*}\right)^{-1}\left[C_{1}^{*} A_{1}^{*} F_{1}+C_{1}^{*} E_{1}^{*} F_{2}\right], \\
& B_{v}^{*}=B_{s}^{*}\left(C_{1}^{*} B_{1}^{*}\right)^{-1}, \quad C_{v}^{*}=C_{s}^{*}, \\
& F_{1}=\left[\begin{array}{llll}
I_{2 \times 2} & \mathbf{0}_{2 \times 2} & \mathbf{0}_{2 \times 2} & \mathbf{0}_{2 \times 2} \\
\mathbf{0}_{2 \times 2} & I_{2 \times 2} & \mathbf{0}_{2 \times 2} & \mathbf{0}_{2 \times 2}
\end{array}\right], \\
& F_{2}=\left[\begin{array}{llll}
\mathbf{0}_{2 \times 2} & \mathbf{0}_{2 \times 2} & I_{2 \times 2} & \mathbf{0}_{2 \times 2}
\end{array}\right] .
\end{aligned}
$$

The next subsection uses the augmented plant to design the model predictive voltage controller.

\subsubsection{Design of the Discrete-Time Model Predictive Voltage Controller}

MPC is essentially a class of computer control algorithms to control the future behavior of a system through the use of an explicit model of the system. At each control step, the MPC algorithm computes an open-loop sequence of controls to optimize the future system behavior. For the MPC design, the system in Eqs. (23) and (24) is considered. Bounds on the manipulated variables are assumed, as follows:

$$
-u^{\max } \leq u_{v}(k) \leq u^{\max },
$$

where $u^{\max }$ is the maximum peak value of the inverter currents.

\subsubsection{Augmented Model}

Equations (15) and (16) are first transformed into an increment model that is appropriate for MPC design purposes [33]:

$$
\begin{aligned}
x_{v}(k+1)-x_{v}(k)= & A_{v}^{*}\left(x_{v}(k)-x_{v}(k-1)\right) \\
& +B_{v}^{*}\left(u_{v}(k)-u_{v}(k-1)\right), \\
y_{v}(k+1)-y_{v}(k)= & C_{v}^{*}\left(x_{v}(k+1)-x_{v}(k)\right),
\end{aligned}
$$

or

$$
\begin{aligned}
\delta x_{v}(k+1) & =A_{v}^{*} \delta x_{v}(k)+B_{v}^{*} \delta u_{v}(k), \\
y_{v}(k+1) & =y_{v}(k)+C_{v}^{*} A_{v}^{*} \delta x_{v}(k)+C_{v}^{*} B_{v}^{*} \delta u_{v}(k),
\end{aligned}
$$

and in final form with integral action:

$$
\begin{aligned}
{\left[\begin{array}{c}
\delta x_{v}(k+1) \\
y_{v}(k+1)
\end{array}\right]=} & {\left[\begin{array}{cc}
A_{v}^{*} & 0 \\
C_{v}^{*} A_{v}^{*} & I
\end{array}\right]\left[\begin{array}{c}
\delta x_{v}(k) \\
y_{v}(k)
\end{array}\right] } \\
& +\left[\begin{array}{c}
B_{v}^{*} \\
C_{v}^{*} B_{v}^{*}
\end{array}\right]\left[\delta u_{v}(k)\right] .
\end{aligned}
$$


By choosing a new state variable vector $\bar{x}(k)=\left(\delta x_{v}(k)\right.$, $\left.y_{v}(k)\right)^{T}$, Eq. (25) the becomes

$$
\begin{aligned}
& \bar{x}(k+1)=\bar{A} \bar{x}(k)+\bar{B} \delta \bar{u}(k), \\
& \bar{y}(k+1)=\bar{C} \bar{x}(k),
\end{aligned}
$$

where

$\bar{A}=\left[\begin{array}{cc}A_{v}^{*} & 0 \\ C_{v}^{*} A_{v}^{*} & I\end{array}\right], \quad \bar{B}=\left[\begin{array}{c}B_{v}^{*} \\ C_{v}^{*} B_{v}^{*}\end{array}\right], \quad \bar{C}=[0 I], \quad \bar{u}=u_{v}$,

\subsubsection{Prediction of State and Output}

Based on the augmented model in Eqs. (26) and (27), the predicted plant output is calculated using control input as the adjustable variable. Suppose that at sampling instant $k$ the output measurement $y(k)$ is available; the future input trajectory is denoted by $\delta \bar{u}(k \mid k), \delta \bar{u}(k+1 \mid k), \ldots, \delta \bar{u}\left(k+N_{c}-1 \mid k\right)$, where $N_{c}$ is the control horizon.

The predicted state and output over a prediction horizon $N_{p}$ are given by

$$
\begin{aligned}
& \bar{x}(k+1 \mid k), \bar{x}(k+2 \mid k), \ldots, \bar{x}\left(k+N_{P} \mid k\right), \\
& \bar{y}(k+1 \mid k), \bar{y}(k+2 \mid k), \ldots, \bar{y}\left(k+N_{P} \mid k\right),
\end{aligned}
$$

where $\bar{x}(k+1 \mid k)$ and $\bar{y}(k+1 \mid k)$ represent the future state and output, respectively, at sampling instant $k+j$ using initial $\bar{x}(k \mid k)=\bar{x}(k)$. It is assumed that $N_{c} \leq N_{p}$ and $\delta \bar{u}\left(k+N_{c}+\right.$ $i \mid k)=0\left(i=0,1, \ldots, N_{p}-N_{c}-1\right)$.

It is noted that the predicted state and output can be represented as

$$
\begin{aligned}
& \bar{x}(k+j \mid k)=\bar{A}^{j} \bar{x}(k)+\sum_{i=0}^{j-1} \bar{A}^{j-i-1} \bar{B} \delta \bar{u}(k+i \mid k), \\
& \bar{y}(k+j \mid k)=\bar{C} \bar{A}^{j} \bar{x}(k)+\sum_{i=0}^{j-1} \bar{C} \bar{A}^{j-i-1} \bar{B} \delta \bar{u}(k+i \mid k) .
\end{aligned}
$$

\subsubsection{Optimization}

Denote the following vector $\delta \bar{U}(k)=[\delta \bar{u}(k \mid k), \delta \bar{u}(k+$ $\left.1 \mid k), \ldots, \delta \bar{u}\left(k+N_{c}-1 \mid k\right)\right]^{T}$. An objective function resulting in the control inputs to penalize deviations of the predicted control outputs is first defined from a given reference trajectory $r(k+i \mid k)$ :

$$
\begin{aligned}
V(k)= & \sum_{i=0}^{N_{p}}\|\bar{y}(k+i \mid k)-r(k+i \mid k)\|_{Q(i)}^{2} \\
& +\sum_{i=0}^{N_{c}-1}\|\delta \bar{u}(k+i \mid k)\|_{R(i)}^{2},
\end{aligned}
$$

where $Q(i)$ and $R(i)$ are the weights. Parameters $N_{c}, N_{p}, Q(i)$, and $R(i)$ are all design parameters that can be tuned to give
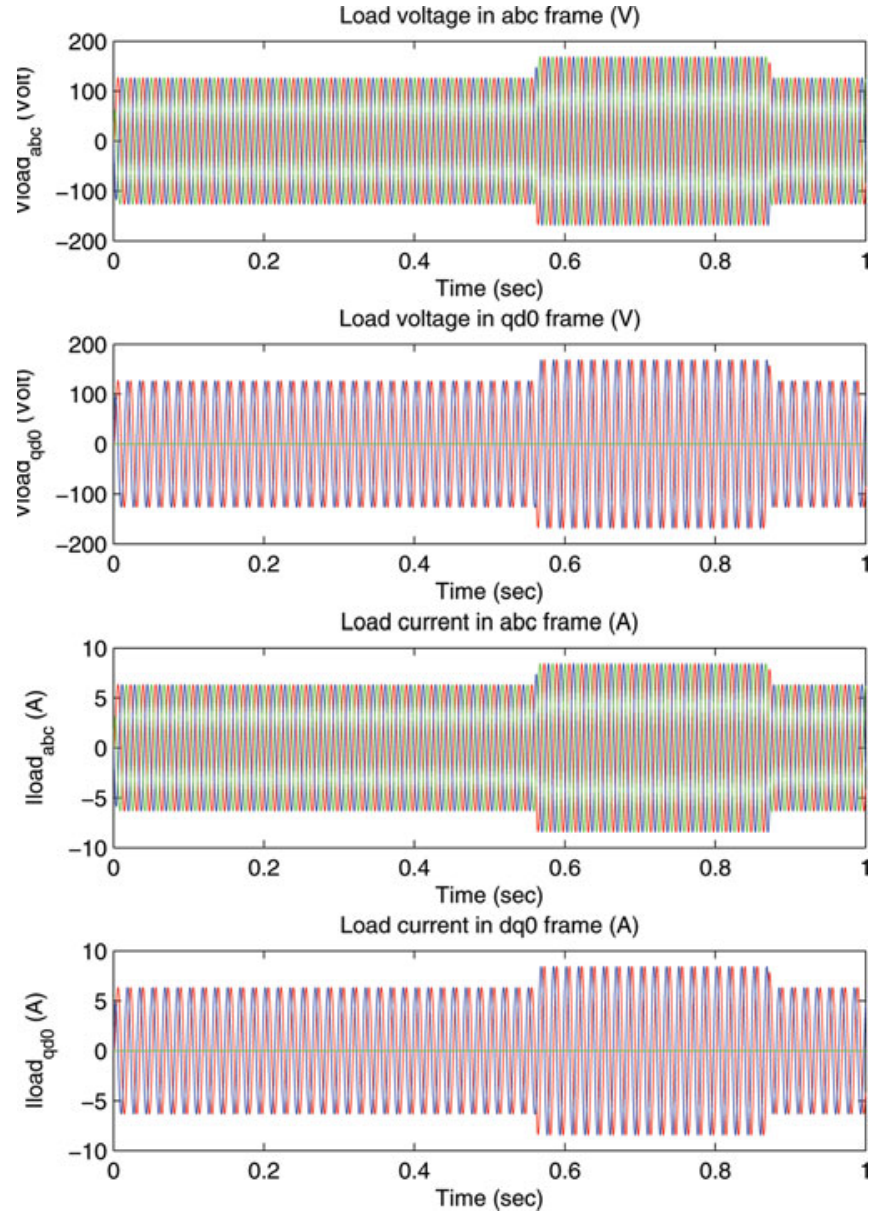

FIGURE 3. Load voltage and current with reference voltage variation.

satisfactory dynamic performance. The optimization problem is subject to the following constraints:

$$
-u^{\max } \leq \bar{u}(k+i \mid k) \leq u^{\max }, \quad i=0,1, \ldots, N_{c}-1 .
$$

It is noted that objective function $V(k)$, as well as the input constraint, can be rewritten in terms of $\delta \bar{U}(k)$ [33]. This leads to the following standard optimization problem:

$$
\min _{\delta \bar{U}(k)} \frac{1}{2} \delta \bar{U}(k)^{T} \Phi \delta \bar{U}(k)+\phi^{T} \delta \bar{U}(k),
$$

subject to $\Omega \delta \bar{U}(k) \leq \omega$,

where $\Phi, \phi, \Omega$, and $\omega$ are matrices of specific type; see [33]. This optimization problem can be solved by quadratic programming. Let the solution of the optimization problem be denoted by

$\delta \bar{U}^{*}(k)=\left[\delta \bar{u}^{*}(k \mid k), \delta \bar{u}^{*}(k+1 \mid k), \ldots, \delta \bar{u}^{*}\left(k+N_{c}-1 \mid k\right)\right]^{T}$. 


\subsubsection{MPC Algorithm}

The idea of MPC is based on the receding horizon control principle, which can be summarized as follows:

(i) at sampling time instant $k$, solve the optimization problem using the current measurement $\bar{y}(k)$;

(ii) the first element of the resulting optimal controller, i.e., $\delta \bar{u}^{*}(k \mid k)$, is applied to the plant in the interval $[k, k+1]$ (the remaining $\left\{\delta \bar{u}^{*}(k+1 \mid k), \ldots, \delta \bar{u}^{*}(k+\right.$ $\left.N_{c}-1 \mid k\right\}$ is disregarded;

(iii) the procedure based on the output measurement $\bar{y}(k+$ $i \mid k)$ is repeated from step (i) for the next sampling instants $i+k(i=1,2, \ldots)$.

\section{PERFORMANCE EVALUATION}

The load voltage reference to be traked by the MPC is given in RMS value, then generated in the three-phase $a b c$ reference
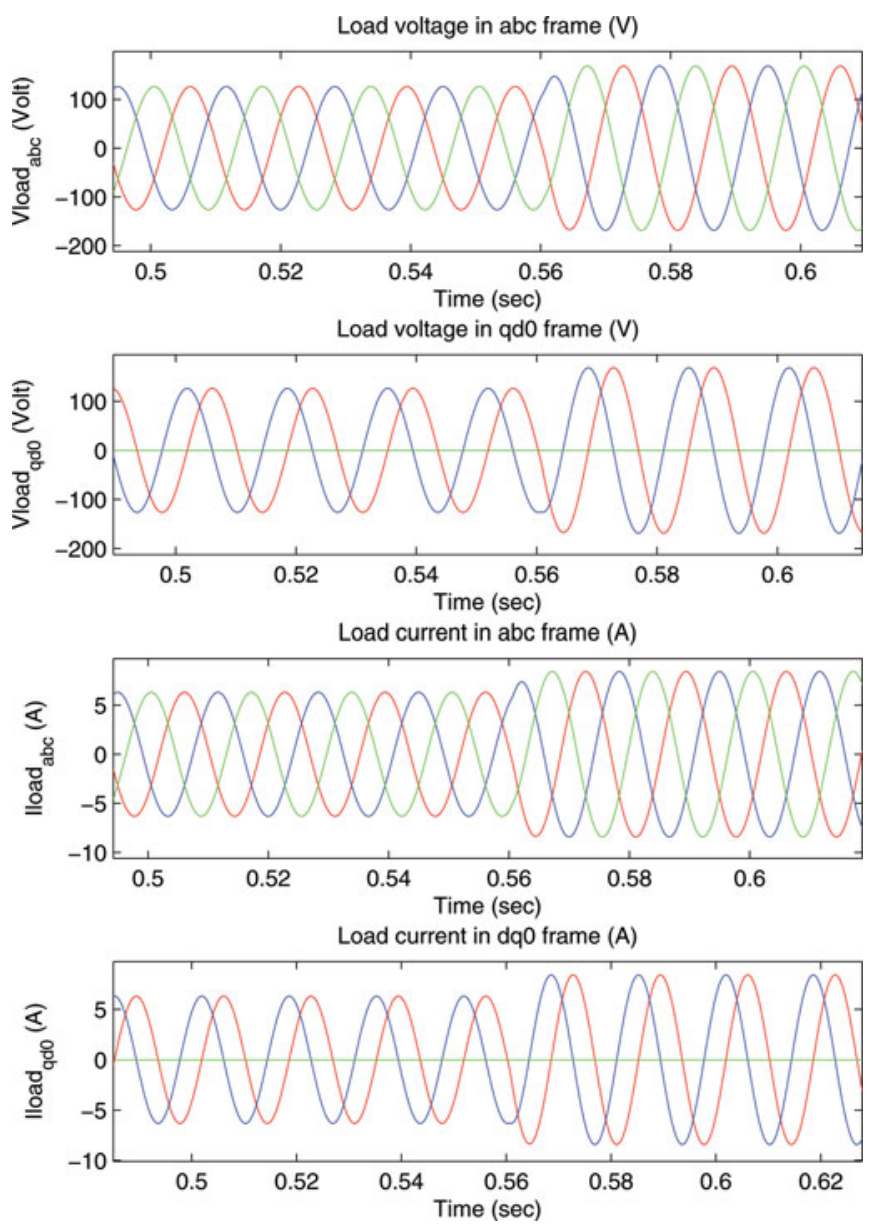

FIGURE 4. Load voltage and current at transition from reference voltage $90 \mathrm{~V}$ (RMS) to reference voltage $120 \mathrm{~V}$ (RMS) of Figure 3. frame, then transformed to the $q d 0$ stationary reference frame needed for the controller. It is therefore required for different loading conditions to measure load voltage and current in the $a b c$ reference frame with the required reference frequency of $60 \mathrm{~Hz}$ and phase angle difference of $120^{\circ}$ between the three phases. The measurements are also shown in the $q d 0$ stationary reference to further explain the effectiveness of the controller by observing the $q d 0$ load voltage and current, especially the zero-sequence value in different loading conditions. The tests focus on the stability of the controller to regulate the voltage and frequency in cases of microgrid reference voltage variation, load variation, single- and two-phase operation, and unbalanced loading.

The performance evaluation is intended to show the effectiveness of the controller design under different operation scenarios. The controller is designed based on the nominal system of Eqs. (13) and (14) and is applied to the plant that presents the three-phase inverter, filter, and loads described by
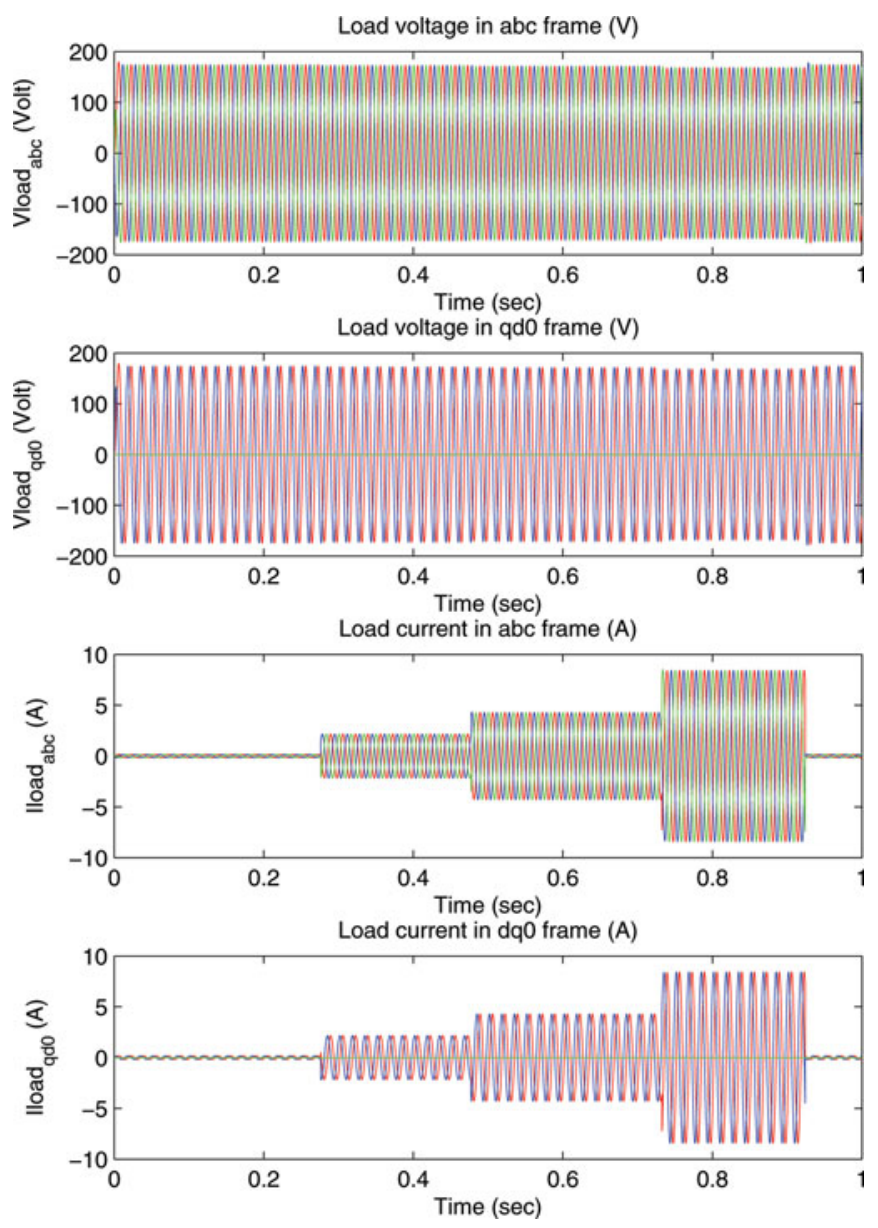

FIGURE 5. Load voltage and current with load resistance variation. 
Quantity

VSI filter inductance $L_{i n v}$ VSI filter capacitance $C_{i n v}$ Load side capacitors $C_{\text {Load }}$ Transformer inductance $L_{T}$ Transformer resistance $R_{T}$ Transformer turns ratio $t_{r}$ System nominal frequency $f_{0}$ DC bus voltage $V_{D C}$

TABLE 1. Parameters of the system in Figure 1

Eqs. (5) and (8) with $\vec{I}_{\text {Load } a b c}=\vec{V}_{\text {Load }_{a b c}} / R_{\text {load }}$. Here $R_{\text {load }}$ is an uncertain load parameter.

The parameters of the test system shown in Figure 1 are given in Table 1.

For performance evaluation and verification of the proposed controller, the following tests are performed.
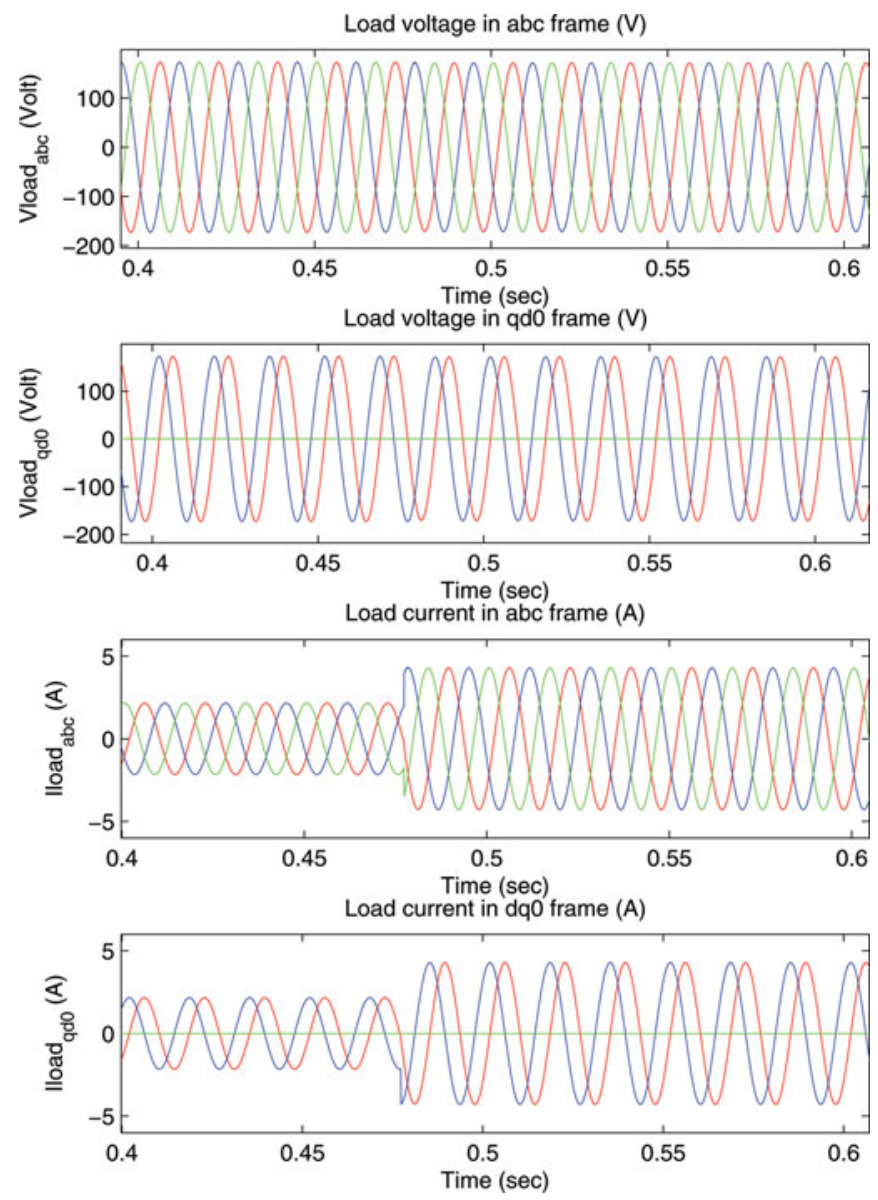

FIGURE 6. Load voltage and current at transition of load resistance variation of Figure 5.
Test 1: Maintain the magnitude and the frequency of the island voltage at desired reference voltage levels.

In this test, the $q d$-reference voltage (RMS) value is step changed from 90 to $120 \mathrm{~V}$, then back to $90 \mathrm{~V}$, with a load resistance of $20 \Omega$; the simulation is done for $1 \mathrm{sec}$, as shown in Figure 3. Transient from 90 to $120 \mathrm{~V}$ (RMS) is shown in Figure 4. The results show that the controller is capable of tracking the reference voltage magnitude and frequency with zero steady-state error. The load and inverter line currents are increased to accommodate the increased demand of the load due to microgrid voltage increment.

Test 2: Maintain the stability of the islanded microgrid in the presence of load uncertainties, which are presented by load resistance variations.

Load resistance is step decreased from open circuit to 80, 40 , and $20 \Omega$, and finally to open-circuit case gain, as shown in Figure 5. As the load resistance changes to smaller value, the VSI has to increase its real current to compensate the increase of real power of the load. Step changes show the effectiveness of the proposed controller in dealing with abrupt
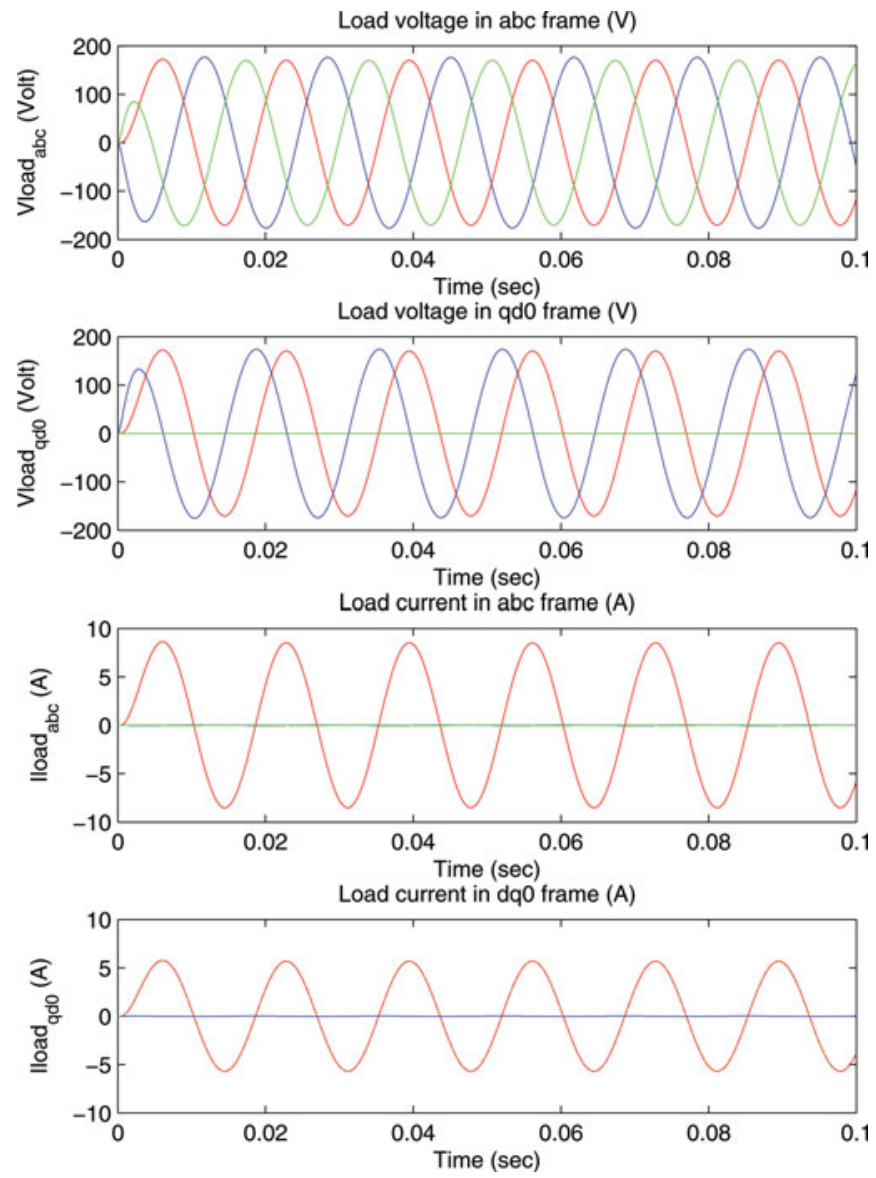

FIGURE 7. Load voltage and current with single-phase load operation. 
load variations. Transient from 80 to $40 \Omega$ is shown in Figure 6.

Test 3: Maintain the voltage stability of the islanded microgrid with single- and two-phase load operation.

The simulation for both cases is performed for $0.1 \mathrm{sec}$. To simulate single-phase operation, the resistance of phase a is set at $20 \Omega$, while phases $b$ and $c$ are open circuited. The simulation results are presented in Figure 7 . It is observed that the controller adjusts the microgrid load voltage at $120 \mathrm{~V}$ (RMS), while the line current is drawn by phase $a$ only.

When testing two-phase operation, phase $a$ and $b$ resistances are set to $20 \Omega$, while phase $c$ is open circuited. The simulation results are presented in Figure 8. It is observed that the controller adjusts the microgrid load voltage at $120 \mathrm{~V}$ (RMS), while line currents are drawn by phase $a$ and $b$.

Test 4: Maintain the voltage stability of the islanded microgrid for unbalanced loading.
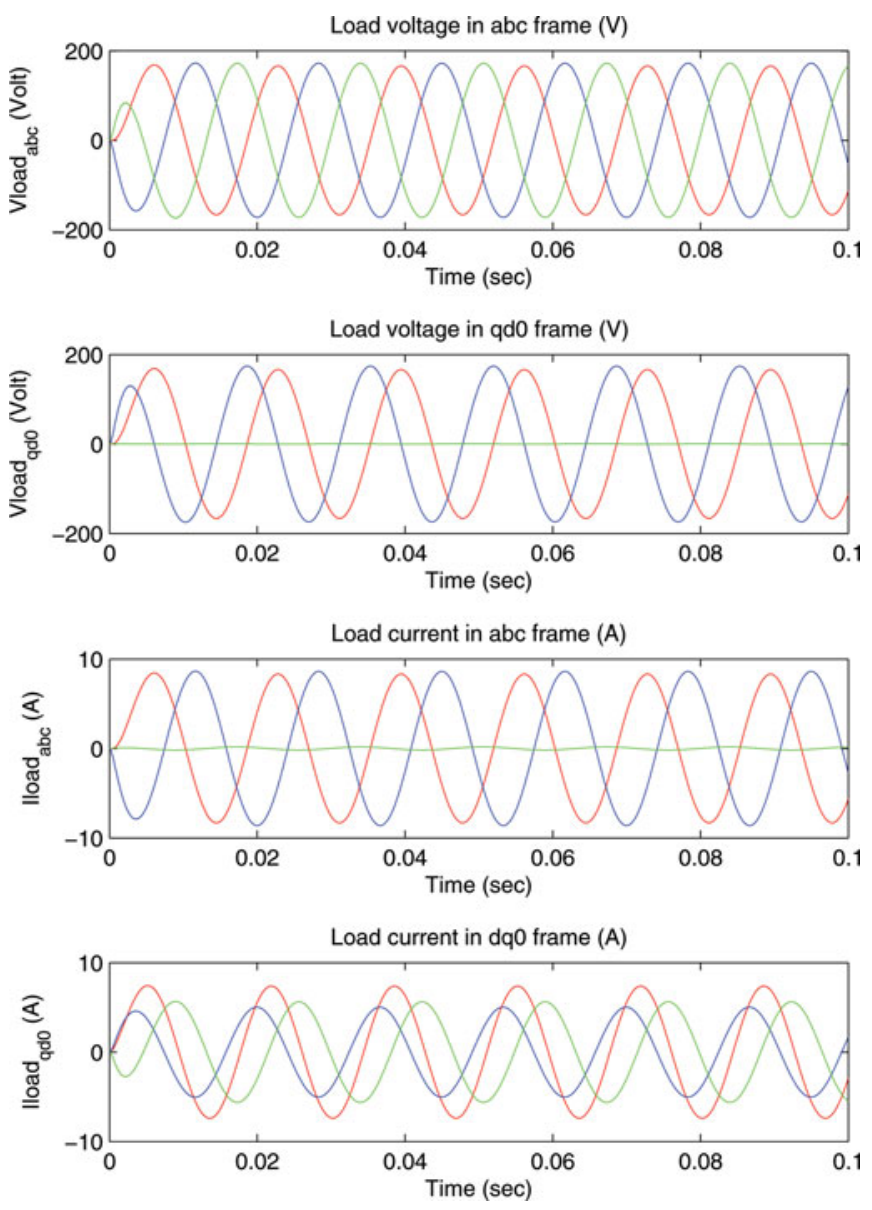

FIGURE 8. Load voltage and current two-phase load operation.
Assuming a full load resistance of $20 \Omega$, phase $a$ is $50 \%$ loaded, phase $b$ is $80 \%$ loaded, and phase $c$ is $70 \%$ loaded. The simulation is performed for $0.1 \mathrm{sec}$. The results are presented in Figure 9.

Test 5: Transient performance for transition from open circuit to short circuit at the output terminals using the proposed controller.

The final verification to the proposed control algorithm is for the ability to limit the inverter currents under short circuits at the output terminal, as shown in Figs. 10 and 11 .

(a) With constrained MPC voltage controller: The proposed MPC voltage controller provides the reference inverter currents, which are constrained to prevent the inverter currents from exceeding the rated values. In this case, there is no need for a separate overload current limiting function as it is embedded in the MPC design. Figure 10 shows the system response to the transition from open circuit to short circuit.
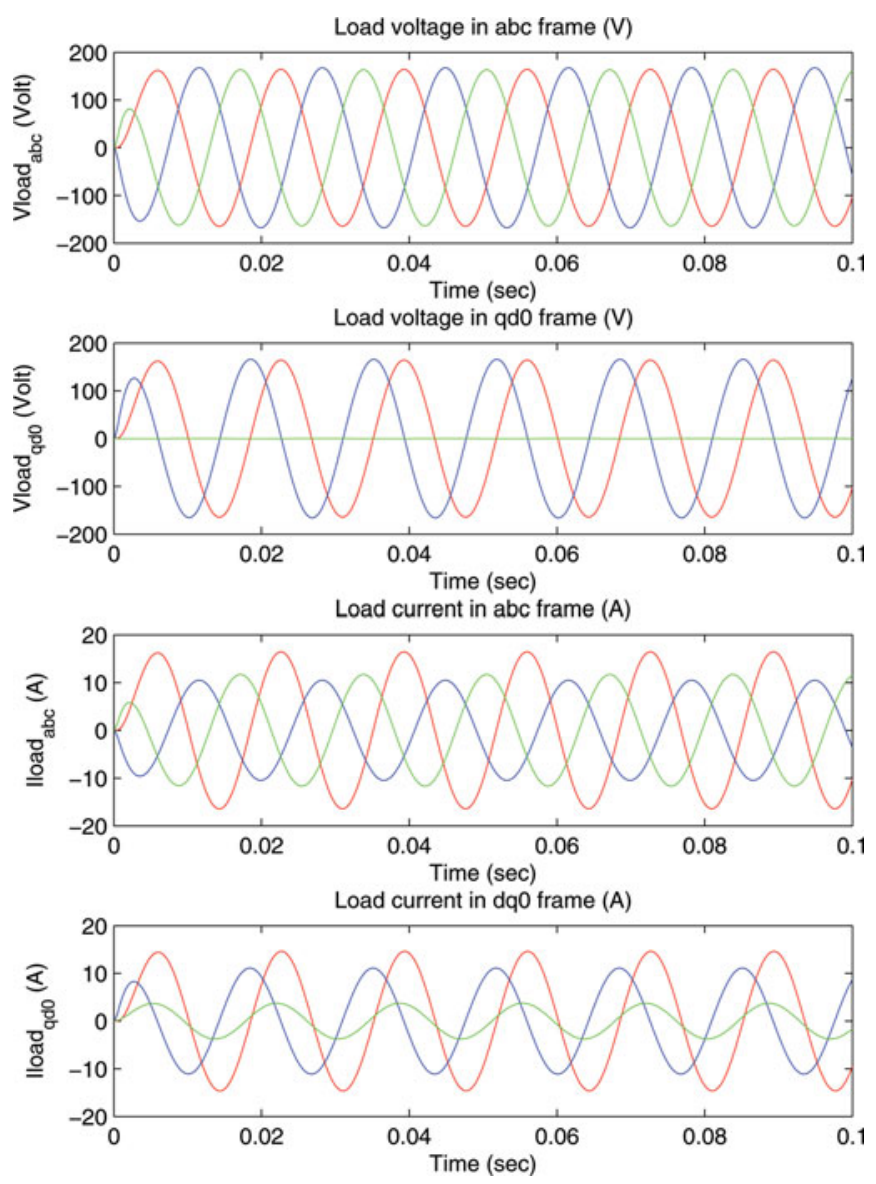

FIGURE 9. Load voltage and current with unbalanced loading. 

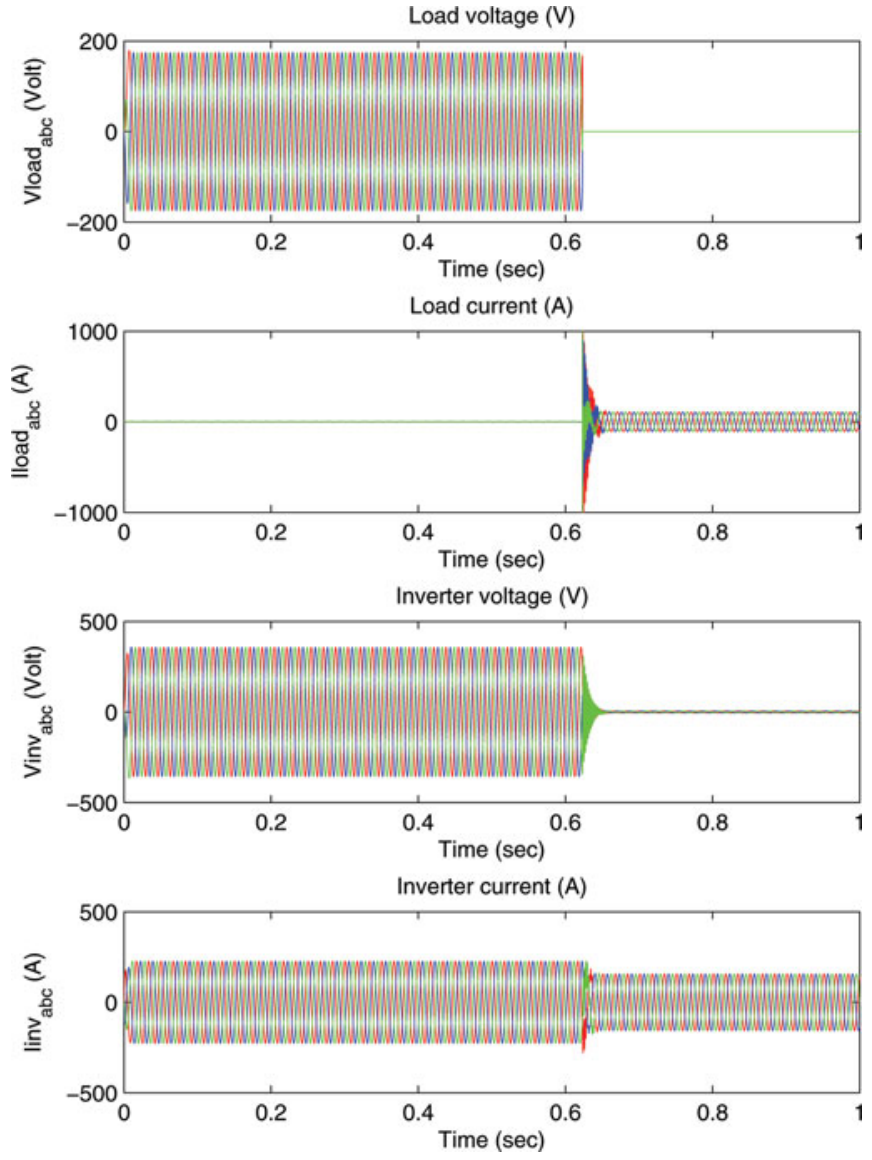

FIGURE 10. Transition from open circuit to short circuit.

(b) With RSP voltage controller: This test is performed using the RSP for voltage controll as proposed in [20]. In this method, the current limiting function is performed to limit the inverter current commands generated by the RSP voltage controller. This limiting function is not included in the RSP voltage controller design, and is accomplished by limiting the magnitude of the inverter current commands vector to $300 \%$ of the rated values and maintaining its original direction. Figure 11 shows the response to the transition from open circuit to short circuit, mainly showing the response of the inverter currents with and without the current limiting function. Large overshoot is observed in the case of not using a current limiter, which is likely to damage the inverter device.

The simulation results of Tests 1-4 show that, in cases of a balanced three-phase load and single-phase load operations, the zero component of the load current in the qd0 frame is always zero, while in cases of an unbalanced three-phase load and two-phase load operations, it is non-zero. It is also ob-
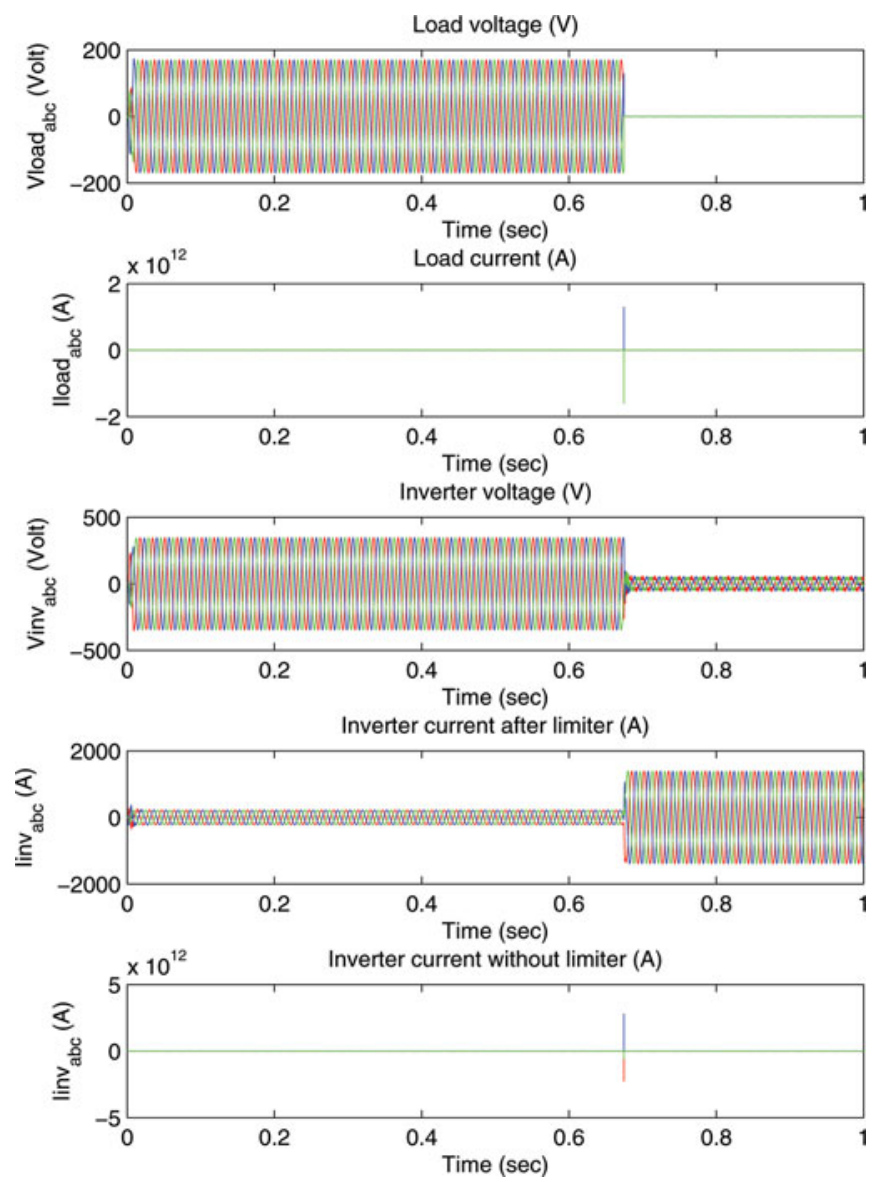

FIGURE 11. Transition from open circuit to short circuit in case of using RSP control.

served that the zero component of the load voltage in the $q d 0$ frame is always zero for all loading conditions.

\section{CONCLUSION}

A proposed dual-loop controller for the V-f control of a VSI in an islanded microgrid is presented in this article. The controller design is based on employing a cascaded control strategy of two loops. The inner loop is a fast response current controller designed using sliding-mode control to regulate the VSI current under overload conditions. The outer loop is a voltage controller designed using MPC to regulate the microgrid voltage and frequency. A dynamic model of a test system and controller is developed. The performance evaluation of the proposed control strategy is tested under different operating conditions, showing the robustness of the proposed strategy for autonomous operation of SMGs.

\section{REFERENCES}

[1] Strzelecki, R., and Benysek, G., Power Electronics in Smart Electrical Energy Networks, London: Springer-Verlag, Chap. 1., pp. 1-5, 2008. 
[2] Moaddabi, N., Hosseinian, S. H., and Gharehpetian, G. B., "Practical framework for self-healing of smart grids in stable/unstable power swing conditions," Elect. Power Compon. Syst., Vol. 40, No. 6, pp. 575-596, 2012.

[3] Moaddabi, N., and Gharehpetian, G. B., "Wide-area method for self-healing of smart grids in unstable oscillations," Elect. Power Compon. Syst., Vol. 41, No. 4, pp. 365-382, 2013.

[4] Erseghe, T., and Tomasin, S., "Power flow optimization for smart microgrids by SDP relaxation on linear networks," IEEE Trans. Smart Grid, Vol. 4, No. 2, pp. 751-762, 2013.

[5] Girgis, A. A., and Makram, E. B., "Innovations in power systems," Proceedings of 14th Int. Middle East Power Systems Conference (IEEE MEPCON'10), Cairo, Egypt, 19-21, December 2010.

[6] Gellings, C. W., The Smart Grid: Enabling Energy Efficiency and Demand Response, Liburn, GA: Fairmont Press, Chap. 1, pp. 1-5, 2009.

[7] Dugan, R. C., McGranaghan, M. F., Santos, S., and Wayne Beaty, H. , Electrical Power Systems Quality, 2nd ed. New York: McGraw Hill, Chap. 9, pp. 386-388, 2004.

[8] Keyhani, A., Marwali, M., and Dai, M., Integration of Green and Renewable Energy in Electric Power Systems, Hoboken, NJ: John Wiley \& Sons, Chap. 2, pp. 26-30, 2010.

[9] IEEE, "IEEE Standard for interconnecting distributed resources with electric power systems," IEEE Standard 1547-2003, pp. 1-16, July 2003.

[10] Dou, C. X., Liu, D. L., Jia, X. B., and Zhao, F., "Management and control for smart microgrid based on hybrid control theory," Elect. Power Compon. Syst., Vol. 39, No. 8, pp. 813-832, 2011.

[11] Piagi, P., and Lasseter, R. H., "Autonomous control of microgrids," Proceedings of IEEE Power Engineering Society General Meeting, 18-22, Montreal, June 2006.

[12] Lasseter, R. H., and Piagi, P., Control and Design of Microgrid Components, Tempe, AZ: PSERC Publication, Chap. 3, pp.19-26, 2006.

[13] Nikkhajoei, H., and Lasseter, R. H., "Distributed generation interface to the CERTS microgrid," IEEE Trans. Power Deliv., Vol. 24, No. 3, pp. 1598-1608, 2009.

[14] Sao, C. K., and Lehn, P. W., "Autonomous load sharing of voltage source converters," IEEE Trans. Power Deliv., Vol. 20, No. 2, pp. 1009-1016, 2005.

[15] Yu, X., Khambadkone, A. M., Wang, H., and Terence, S. T. S., "Control of parallel-connected power converters for low-voltage microgrid-Part I: A hybrid control architecture," IEEE Trans. Power Electron., Vol. 25, No. 12, pp. 2962-2970, 2010.

[16] Abo-Al-Ez, K. M., Xia, X., and Zhang, J., "Smart interconnection of a PV/wind DG micro grid with the utility distribution network," Proceedings of Industrial and Commercial Use of Energy Conference (ICUE), Cape Town, South Africa, 14-17 August 2012.

[17] Ahmed, A., Radwan, A., and Abdel-Rady Mohamed, Y., "Linear active stabilization of converter-dominated DC microgrids," IEEE Trans. Smart Grid, Vol. 3, No. 1, pp. 203-216, 2012.

[18] Li, Y., Vilathgamuwa, D. M., and Loh, P. C., "Robust control scheme for a microgrid with PFC capacitor connected," Proc. IEEE Industry Applications Conference, 40th IAS Annu. Meeting, Vol. 4, pp. 2441-2448, 2-6 October, 2005.
[19] Marwali, M., and Keyhani, A., "Control of distributed generation systems - part I: Voltages and current control," IEEE Trans. Power Electron., Vol. 19, No. 6, pp. 1541-1550, 2004.

[20] Marwali, M., Dai, M., and Keyhani, A., "Robust stability analysis of voltage and current control for distributed generation systems," IEEE Trans. Energy Convers., Vol. 21, No. 2, pp. 516-526, 2006.

[21] Karimi, H., Davison, E., and Irvani, R., "Multivariable servomechanism controller for autonomous operation of distributed generation unit: Design and performance evaluation," IEEE Trans. Power Syst., Vol. 25, No. 2, pp. 853-865, 2010.

[22] Bahrani, B., and Ruler, A., "Model predictive-based voltage regulation of an islanded distributed generation unit," IEEE Conference on Energy Conversion Congress and Exposition (ECCE), pp. 465-472, Phoenix, AZ, 17-22 September 2011.

[23] Gemma, L., Performance Limitations in the Robust Servomechanism Control Problem for Discrete and Sampled Data System, Ph.D. Thesis, University of Toronto, December 2000.

[24] Mayne, D. Q., Rawlings, J. B., Rao, C. V., and Scokaert, P. O. M., "Constrained model predictive control: Stability and optimality," Automatica, Vol. 36, No. 6, pp. 789-814, 2000.

[25] Qin, S. J., and Badgwell, T., "A survey of industrial model predictive control technology," Control Eng. Pract., Vol. 11, No. 7, pp. 733-764, 2003.

[26] Otomega, B., Marinakis, A., Glavic, M., and Van Cutsem, T., "Model predictive control to alleviate thermal overloads," IEEE Trans. Power Syst., Vol. 22, No. 3, pp. 1384-1385, 2007.

[27] Ekpenyong, U. E., Zhang, J., and Xia, X., "An improved robust model for generator maintenance scheduling," Elect. Power Syst. Res., Vol. 92, pp. 29-36, 2012.

[28] Xia, X., Zhang, J., and Elaiw, A. M., “An application of model predictive control to the dynamic economic dispatch of power generation," Control Eng. Pract., Vol. 19, pp. 638-648, 2011.

[29] Elaiw, A. M., Xia, X., and Shehata, A. M., "Application of model predictive control to optimal dynamic dispatch of generation with emission limitations," Elect. Power Syst. Res., Vol. 84, pp. 31-44, 2012.

[30] Elaiw, A. M., Xia, X., and Shehata, A. M., "Minimization of fuel costs and gaseous emissions of electric power generation by model predictive control," Math. Prob. Eng., Vol. 3013, Article ID 906958, 2013.

[31] Zhang, J., and Xia, X., "A model predictive control approach to the periodic implementation of the solutions of the optimal dynamic resource allocation problem," Automatica, Vol. 47, pp. 358-362, 2011.

[32] van Staden, A. J., Zhang, J., and Xia, X., "A model predictive control strategy for load shifting in a water pumping scheme with maximum demand charges," Appl. Energy, Vol. 88 pp. 4785-4794, 2011.

[33] Maciejowski, J. M., Predictive Control with Constraints, Harlow, England: Prentice Hall, Chap. 3, pp. 73-90, 2002.

\section{BIOGRAPHIES}

Khaled M. Abo-Al-Ez received the B.S., M.S., and Ph.D. degrees from the Department of Electrical Engineering, 
Mansoura University, Mansoura, Egypt, in 2000, 2003, and 2011, respectively. He was a visiting scholar at the University of New Brunswick, Fredericton, Canada from Sept. 2005 to Aug. 2006. He was a post doctoral fellow at the Centre of New Energy Systems (CNES) in the University of Pretoria, Pretoria, South Africa from Mar. 2012 to Feb. 2013. Dr. Abo-Al-Ez is currently an assistant professor of electrical power engineering in Mansoura University, Mansoura, Egypt. His research interests are renewable energy generation systems, decentralized generation, mathematical and computer modeling, power system optimization, power system planning and automation, power electronics, power quality and smart grids.

Ahmed Elaiw received his Ph.D. from Budapest University of Technology and Economics, Budapest, Hungary. He was a post doctoral fellow at the Centre of New Energy Systems (CNES) in the University of Pretoria, Pretoria, South Africa from Aug. 2007 to Jul. 2008. Also, he was a visiting professor at CNES, University of Pretoria from Jun. 2012 to Aug. 2012. Currently, he is an associate professor of Mathematics at King Abdulaziz University, Saudi Arabia. His research interests include control systems, power system optimization and smart grids.

Xiaohua Xia is a professor in the Electrical, Electronic and Computer Engineering at the University of Pretoria, South Africa, director of the Centre of New Energy Systems, and the director of the National Hub for the Postgraduate Programme in Energy Efficiency and Demand-side Management. Prof. Xia is a fellow of the Institute for Electronic and Electrical Engineers (IEEE), a fellow of the South African Academy of Engineering (SAAE), and a member of the Academy of Science of South Africa (ASSAf). He has an A rating from the South African National Research Foundation (NRF). He has been an associate editor of Automatica, IEEE Transactions on Circuits and Systems II, IEEE Transactions on Automatic Control, and specialist editor (control) of the SAIEE Africa Research Journal. His research interests are control systems and automation, and more recently, the modeling and optimization of energy systems. 